\title{
Local applications of GM-CSF induce the recruitment of immune cells in cervical low-grade squamous intraepithelial lesions.
}

Pascale Hubert ${ }^{1}$, Jean Doyen ${ }^{2}$, Xavier Capelle ${ }^{2}$, Mohammad Arafa ${ }^{1}$, Virginie Renoux ${ }^{1}$, Bettina Bisig ${ }^{1}$, Laurence Seidel ${ }^{3}$, Brigitte Evrard ${ }^{4}$, Latifa Bousarghin ${ }^{1 \#}$, Colette Gerday ${ }^{2}$, Jacques Boniver ${ }^{1}$, Jean-Michel Foidart $^{2}$, Philippe Delvenne ${ }^{1}$, Nathalie Jacobs ${ }^{1 *}$

(1) Dept of Pathology, GIGA-CANCER/GIGA-I3 and (2) Dept of Gynecology, (3) Dept of Biostatistics (4) Dept of Pharmaceutical Technology, University of Liège, B23 CHU Sart-Tilman, 4000 Liège, Belgium, ${ }^{\sharp}$ Current address: Laboratoire de Microbiologie Immunologie, UPRES-EA 1254, Université de Rennes I, 2 Avenue du Professeur Léon Bernard, 35043 Rennes, France

${ }^{*}$ Corresponding author: $\mathrm{Dr}$ N. Jacobs, Dept of Pathology, GIGA-I3, University of Liège, B23 CHU Sart-Tilman, 4000 Liège, Belgium

Phone: +32 4366 4282; Fax: +32 4366 9583; E-mail: n.jacobs@uld.ac.be

Running title: Local GM-CSF treatment of HPV-cervical lesions 
Abstract
Problem
Quantitative alterations of antigen-presenting cells (APC) in (pre)neoplastic lesions of the uterine cervix associated with human papillomavirus (HPV) infection suggest a diminished capacity to capture viral antigens and to induce a protective immune response.

\section{Method of study}

To test if a cervical application of GM-CSF could restore an immune response against HPV in women with cervical low-grade squamous intraepithelial lesions (LSIL). We performed two clinical trials with11 healthy women and 15 patients with LSIL.

\section{Results}

GM-CSF applications were well tolerated in all enrolled women and no difference in toxicity between the treated and placebo groups was observed during the follow up (until 30 months). Interestingly, in the GM-CSF treated group, a significant increased APC and cytotoxic T lymphocyte infiltration was observed in the cervical biopsies with no change in regulatory $\mathrm{T}$ cell numbers. All the HPV $16^{+}$patients exhibited an immune response against HPV16 after GM-CSF applications, as shown by $\mathrm{NK}$ and/or $\mathrm{T}$ cells producing IFN- $\gamma$ whereas no cellular immune response was observed before the treatment. Moreover, the anti-VLP antibody titers also increased after the treatment.

\section{Conclusion}

These encouraging results obtained from a limited number of subjects justify further study on the therapeutic effect of APC in cervical (pre)neoplastic lesions. 
Key words: clinical trial, Granulocyte Macrophage-Colony Stimulating factor (GM-CSF), human papillomavirus, immune response, safety, uterine cervical lesion 


\section{Introduction}

Even if prophylactic vaccines against human papillomavirus (HPV) are now available, morbidity and mortality caused by HPV infection still represent a major health problem with very high direct and indirect costs ${ }^{1}$. Furthermore, the protection is restricted to 2 HPV types involved in $30-70 \%$ of pre-cancerous lesions (squamous intraepithelial lesions, SIL). Incomplete type coverage is especially problematic in developing countries where no effective screening programs are available as an alternative approach for reducing cervical cancer risk associated with minor oncogenic HPV types. The vaccination blocks HPV primary infection by inducing high titers of neutralizing antibodies, but does not accelerate clearance of the virus in pre-existing infections ${ }^{2}$. This could be linked to the fact that cell-mediated immunity is critical for the clearance of HPV-associated lesions ${ }^{3-5}$. Moreover, the current surgical methods for treating SIL may generate complications, e.g. pregnancy complications ${ }^{6}$ and persistence and/or recurrence of SIL occur in $5-25 \%$ of patients ${ }^{7}$. All these facts underlie the need for other therapeutic protocols.

Most SIL are characterized by a decreased density and function of antigen-presenting cells such as dendritic and Langerhans cells $(\mathrm{DC} / \mathrm{LC})$ in comparison with the normal paired squamous epithelium ${ }^{8,9}$. However, Granulocyte Macrophage-Colony Stimulating factor (GMCSF) can restore the colonization of DC/LC in a neoplastic epithelium transplanted in vivo in NOD/SCID mice ${ }^{10}$. This cytokine is produced by 
keratinocytes and a correlation has been observed in vivo between the levels of GM-CSF produced by some carcinomas and the distribution/differentiation of tumor-associated DC ${ }^{11}$. Moreover, in vitro DC specifically induce apoptosis of keratinocytes transformed by HPV, whereas normal keratinocytes are not affected ${ }^{12}$. This apoptotic effect of DC is not restricted to HPV-transformed keratinocytes. Manna et al.

${ }^{13}$ have also demonstrated a direct tumoricidal effect of DC on breast carcinoma cells. The safety of GM-CSF injected subcutaneously ${ }^{14,15}$ or intradermally ${ }^{16}$ to patients with cancer was previously evaluated, but to our knowledge, the tolerability of topical GM-CSF applications on a mucosal surface has never been assessed.

The purpose of this study was to establish a proof of concept for a treatment based on local applications of a GM-CSF-containing gel. We therefore evaluated the safety and the ability of this gel to induce the recruitment of DC/LC and lymphocytes into an epithelium infected by HPV and to elicit an immune response against HPV-infected cells. In order to have a long follow up (more than 6 months this study was performed on patients with low-grade SIL (LSIL) to circumvent the risk of cancer development.

\section{Materials and Methods}

\section{Patients}

Eleven women without cervical lesions were enrolled for a phase la clinical trial. For safety reasons and to be able to have a 6-month follow up without treatment, we chose to include in phase Ib clinical trial patients with LSIL. The eligibility criteria for patients were the persistence of LSIL and/or detection of oncogenic HPV for a minimum 
of three months with a median of 8.5 months for the GM-CSF group and 6 months for the placebo group (no statistical difference). One hundred ninety two patients were screened and fifteen patients with LSIL were enrolled (Fig. 1, Table 1).

Vital signs (heart rate, blood pressure and oral temperature), local symptoms (pain, redness, swelling, inflammation), serious and other adverse events were recorded in the Case Report Form (CRF) of each patient.

HPV genotyping was determined using a PapilloCheck Test Kit (gift from Greiner Bio One, Frickenhausen, Germany) ${ }^{17}$ (Table 1) and the viral load of oncogenic HPV was estimated by Hybrid Capture II (Digene, Venlo, Netherlands) at the first (visit A) or the second visit (B) and at the end of the clinical protocol.

These clinical protocols were approved by the local ethics committee of the University Hospital of Liège.

\section{Clinical protocol}

Patients received 1 (healthy women) or 4 (patients with LSIL) applications of 3-4 $\mathrm{ml}$ GM-CSF (or placebo) in polycarbophil gel separated by 3 days. They were followed for one week or for a period of 6-7 months for the phase la and the phase $\mathrm{lb}$ clinical trial, respectively. A late visit (26-30 months) was also performed for the phase lb clinical trial.

The polycarbophil gel $(1.0 \% \mathrm{w} / \mathrm{w})$ was prepared by dispersing Noveon AA1 (Noveon, Brussels, Belgium) in purified water. The mixture was stirred until thickening occurred and was then neutralized by drop wise addition of $40 \%(\mathrm{w} / \mathrm{w})$ tromethamol, until a transparent gel appeared. The quantity of tromethamol was adjusted to achieve a gel of $\mathrm{pH} 5.5^{10}$. 
For the active formulation, GM-CSF (Amoytop Biotech, Xiamen, China) was incorporated into the hydrogel at a concentration of $400,000 \mathrm{IU} / \mathrm{ml}$, $800,000 \mathrm{IU} / \mathrm{ml}$ or $1,000,000 \mathrm{IU} / \mathrm{ml}$ for the phase la clinical trial and $800,000 \mathrm{IU} / \mathrm{ml}$ for the phase $\mathrm{lb}$ clinical trial. The first administration of the gel was made by a senior gynecologist. The other applications were self-administered at bedtime with a polystyrene applicator (Besins Healthcare, Belgium).

At visit A (week -35 to -5 ) and B (week -21 to -1 ) a colposcopy and sampling for viral detection and DNA load determination were performed. GM-CSF or the placebo gel was applied at visit C (Week 0). Follow up was performed at visit $D$ (week 2), visit $E$ (week 6 to 15) and visit $F$ (week 23 to 42 ).

\section{Keratinocyte proliferation assay}

Normal keratinocytes $(\mathrm{KN})$, HaCat cell line and HPV-transformed keratinocyte cell lines (CK2, CaSki, SiHa and KT1F4) were cultured $\left(5 \times 10^{3}\right.$ cells/well) in 96-well plates (Nunclon Surface, NUNC) with or without GM-CSF $(63 \mu \mathrm{g} / \mathrm{ml}-800000 \mathrm{U} / \mathrm{ml})$. Proliferation was measured after $48 \mathrm{~h}$ at $37^{\circ} \mathrm{C}$, following an $18 \mathrm{~h}$ incubation with $0.4 \mu \mathrm{Ci} /$ well of $\left[{ }^{3} \mathrm{H}\right]$ thymidine $(6.7 \mathrm{Ci} / \mathrm{mmol}$, Moravek Biochemicals, Brea, CA). DNA was harvested by an automated sample harvester (Packar, Canberra, Tilburg, The Netherlands) and thymidine incorporation was analyzed using a liquid scintillation counter (Top Count, Packard, Canberra).

The assessment of cell proliferation in vivo was performed on biopsies by using an anti-Ki-67 antigen antibody (clone MIB-1 from Dako) following a previously described procedure ${ }^{8}$. Ki-67 antigen staining was evaluated by analyzing the localization of positive cells and 
expressing the proliferation as normal when the positive cells were present in the basal layer, low when positive cells reached the first third of the epithelium and moderate to high when the positive cells were present in the second or the last third of the epithelium.

\section{Immunostaining and systemic immune response}

The density of immune cells in biopsies was assessed by immunoperoxidase detection with anti-CD1a (Novocastra, Newcastle, UK) and anti-CD8 (Dako, Glostrup, Denmark) monoclonal antibodies (mAb) for DC/LC and CTL, respectively, as described previously ${ }^{18}$. NK cells were detected with NKp46 mAb (R\&D Systems, Oxon, Belgium) and regulatory $T$ cells (Treg) were stained with Foxp3 mAb (eBiosience, UK). The results were expressed as ratios by dividing the values obtained after treatment by the values before treatment.

The cellular immune response was evaluated by IFN- $\gamma$ intracellular staining on PBMC stimulated with the E7 HPV16 protein (gift from GSK Biologicals, Rixensart, Belgium) and L1 HPV16 Virus-like particles (VLP) at each visit as described previously ${ }^{19}$. Briefly, PBMC (2x $10^{6} / \mathrm{ml}$ ) in $5 \mathrm{ml}$ round bottom polypropylene tubes containing X-vivo 20 medium (BioWhittaker, Cambrex Bio Science, Verviers, Belgium, supplemented with $20 \mathrm{U} / \mathrm{ml} \mathrm{IL-2}$ ) were cultured overnight at $37^{\circ} \mathrm{C}$ with or without the E7 HPV16 protein and L1 HPV16 VLP. HPV16 VLP were produced in insect cells using a recombinant baculovirus encoding HPV 16 L1 protein and were purified as previously described ${ }^{20}$. Brefeldin A (10 $\mu \mathrm{g} / \mathrm{ml}$, Sigma, St. Louis, MO) was added during the last $4 \mathrm{~h}$ of culture. After stimulation, cells were stained for cell surface molecules at $4{ }^{\circ} \mathrm{C}$ for 20 min with anti-CD4-PE, anti-CD8-PerCP, anti- 
CD3-PerCP, anti-CD16-PE and anti-CD56-PE (Becton Dickinson Erembodegem, Belgium). After washing with PBS, cells were fixed and permeabilized with FacsLyse and FacsPerm respectively (Becton Dickinson) according to the manufacturer's instructions. After an additional washing with PBS, the cells were stained with anti-IFN- $\gamma$ FITC (Becton Dickinson) for 20 min at room temperature. After another washing, cells were resuspended in $400 \mu$ of $1 \%$ paraformaldehyde in PBS and acquisition was performed within $24 \mathrm{~h}$ on more than 100,000 events per staining with a flow cytometer (Facsvantage, BectonDickinson). Analysis was performed using CellQuest on an SSC/FSC gate on viable lymphocytes. Results were expressed as the percentages of cytokine positive cells in the defined cell population after background (no activator) was subtracted. Overnight supernatants from PBMC cultures were stored at $-70^{\circ} \mathrm{C}$ and analyzed for IFN- $\gamma$ content in a specific capture ELISA according to the manufacturer's instructions (R\&D Systems).

Plasma samples were used for serological testing for HPV16 and 31 by ELISA assays with HPV16 and 31 VLP L1 as described previously ${ }^{21}$.

\section{Statistical analysis}

Statistical analysis was performed using the Student's $t$ test. The calculation of power gave values from $92 \%$ to $39 \%$ according to the SD (from 0.4 to $0.8 ; 49 \%$ for weighted $\mathrm{SD}=0.7$ ). All calculations were performed with SAS version 9.1 (SAS institute, Cary, NC, USA)

\section{Results}




\section{Safety}

Even if GM-CSF was already used in clinical trials ${ }^{14-16}$, we performed pre-clinical studies because GM-CSF was described to mildly stimulate the growth of HaCat keratinocyte cell line ${ }^{22}$. We confirmed previous results showing the stimulation of HaCat cell proliferation and a slight increased growth of normal keratinocytes, but no significant effect was detected with 4 different $\mathrm{HPV}^{+}$cell lines (Fig. 2a).

The phase la clinical trial was performed because there was no previous information about the potential toxicity of mucosal applications of GM-CSF. The doses used were extrapolated from our data obtained in a murine model ${ }^{10}$. This clinical trial was conducted on 11 normal women with normal cervical cytology (Table 1) who received one application gel containing 400,000 IU/ml (4 women), 800,000 IU/ml (4 women), $1,000,000 \mathrm{IU} / \mathrm{ml}$ (3 women) of GM-CSF. Since no adverse effect was reported, we decided to compare 4 applications of the gel containing the intermediate dose $(800,000 \mathrm{IU} / \mathrm{ml}, \mathrm{n}=10)$ with a placebo gel $(n=5)$ in a second clinical trial including patients with LSIL (Table 1). All women encountered none or only minor and transient side effects with no difference between women receiving gel with or without GMCSF. All patients were examined by gynecologists 6 to 30 months after the second clinical trial and no side effects related to the trial were reported.

To further assess the absence of keratinocyte proliferation in the presence of topical application of GM-CSF, we also performed an antiKi67 labeling ${ }^{23}$ on biopsies taken before or after treatment (visit $D$ and F: 2 weeks and 5 to 10 months after the GM-CSF application, 
respectively). No statistical significant modification in the proliferative index of epithelial cells was observed in women treated with GM-CSF in comparison with the placebo group (Fig. 2b).

\section{Immune response}

DC/LC, cytotoxic $T$ lymphocytes (CTL) density in biopsies was monitored by CD1a (Fig. 3a) and CD8 (Fig. 3b-c) immunostaining, respectively. The different types of staining were scored as previously described ${ }^{18}$ and the results were expressed as ratios compared to the scores obtained before treatment. Significantly higher ratio of CD1a positive cells was observed at visit $F(p=0.0197)$ in GM-CSF-treated group versus placebo (Fig. 3a). GM-CSF also induced similar results for $\mathrm{CD}^{+} \mathrm{T}$ cells, significant data were obtained for visit $\mathrm{F}$ in the stroma adjacent to the lesion $(p=0.040$; Fig. $3 b-c)$. However, the scores of CD1a and CD8 staining were generally higher in the placebo group before the start of the clinical trial (data not shown). NK cells were detected with an NKp46 antibody in cervical biopsies (Fig. 3d). Since the number of $\mathrm{NKp} 46^{+}$cells was low in cervical biopsies, we counted the cells instead of scoring. In the epithelium only few cells were detected (data not shown). In the stroma, an increased NK infiltration was observed at visit $D(p=0.029)($ Fig. $3 d)$.

We also counted the number of Foxp $3^{+}$Treg (Fig. 4 a-b). We were not able to obtain ratios for the infiltration in the epithelium because Treg were not detected in several cervical biopsies (Fig. 4a). Both in the epithelium and in the stroma, we did not observe a significant increase of Foxp $3^{+}$Treg after treatment except for one patient in GM-CSF group 
(Fig. 4 a-b). Interestingly, the patient G2 with the highest number of Foxp $3^{+}$Treg cells (empty symbol in Fig. 4) showed a low score of CD8+ $\mathrm{T}$ cells in the epithelium (empty symbol in Fig. 3b), but not in the stroma or for NK cells (empty symbol in Fig 3c-d). The number of Treg decreased at visit $\mathrm{F}$ (empty symbol in Fig. 4), whereas both $\mathrm{CD} 8^{+} \mathrm{T}$ and NK cells increased (empty symbol in Fig. 3b-d).

Systemic immune responses were also evaluated against HPV16 and 31. Three patients were HPV16 ${ }^{+}$(all in GM-CSF group), which is in concordance with the prevalence of HPV16 in LSIL (24\%) in Belgium ${ }^{24}$ and two patients were $\mathrm{HPV} 31^{+}$(one in GM-CSF and one in placebo group). No T cell response was observed before treatment. There was a substantial increase in the percentage of IFN $\gamma^{+}$cells in PBMC from the 3 patients (G4, G5 and G10), who had received GM-CSF (Fig. 5ab). Depending on the patient and the type of stimulation (E7 or L1VLP), IFN $\gamma$ producing cells were $\mathrm{T}$ lymphocytes $\left(\mathrm{CD}^{+}\right.$or $\left.\mathrm{CD} 4^{+}\right)$or $\mathrm{NK}$ cells. In patients $\mathrm{G} 4$ and $\mathrm{G} 5$, the number of IFN $\gamma^{+}$cells dropped at week 23-42 after the treatment (Fig. 5a-b). We also observed an increased secretion of IFN $\gamma$ in response to E7 and L1-VLP by ELISA assay, except for patient G10 (data not shown). We tested the antiHPV16 response in PBMC from the 12 patients negative for HPV16. A trend for a higher percentage of lymphocytes expressing IFN $\gamma$ after stimulation with HPV16 L1-VLP was observed in the GM-CSF group in comparison with the placebo patients (data not shown).

Before treatment no antibodies or low titers (except for the patient HPV16+ G10) against HPV16 and HPV31 VLP were observed (data not shown). For all the HPV16 ${ }^{+}$patients (G4, G5 and G10), antibodies 
against HPV16 VLP were detected after treatment with GM-CSF (Fig. 5c). Interestingly, the antibody titer in the serum of patient G4 was very high and similar to those observed after vaccination with HPV16 VLP. Both HPV $31^{+}$patients (G4-P1) had antibodies against HPV31 VLP but the patient receiving GM-CSF (G4) had a higher concentration of antibodies than the patient (P1) in the placebo group (Fig. $5 d$ ).

\section{Clinical response}

The clinical status (grade of SIL and viral load) was also checked in the 15 patients enrolled in the phase lb study. Despite the detection of an immune response, we were not able to observe any difference in clinical response, the proportion of patients showing regression or progression was similar in both groups (data not shown). This could be linked to the small cohort of patients, to the high spontaneous regression rate of $\mathrm{LSIL}^{25}$ or to the fact that GM-CSF-treated patients presented, in our study, negative factors (multiple infections, higher viral load and significantly older age $\left.(p=0.03)^{26}\right)$ than those of the placebo-group (Table 1).

\section{Discussion}

In this study, we first demonstrated that the intraepithelial recruitment of antigen-presenting cells by topical applications of GM-CSF is safe and well tolerated (Fig. 2 and Table 1). This is in contrast with other immunomodulators used topically to treat HPV-associated lesions such as imiquimod ${ }^{27-31}$. Moreover, GM-CSF did not induce proliferation of keratinocytes transformed by HPV both in vitro and in vivo (Fig. 2). 
Interestingly, the recruitment of DC/LC in SIL was associated with an immune response against $\mathrm{HPV}$ in $\mathrm{HPV} 16^{+}$patients. Our previous work, both in vitro and in a murine model of HPV-induced intraepithelial neoplasia, demonstrated that GM-CSF is able to stimulate the migration of DC/LC in an epithelium transformed by HPV ${ }^{32}$. We also observed this migration in GM-CSF-treated patient biopsies (Fig. 3 a). A higher infiltration of $\mathrm{CD} 1 \mathrm{a}^{+}$cells was previously described in vulvar intraepithelial lesions in patients who responded to a therapeutic vaccine against $\mathrm{HPV}$, illustrating the importance of APC in the induction of immune response against HPV ${ }^{33}$. Other immunotherapy protocols using tumor cells engineered to secrete GM-CSF also showed increased numbers of activated APC at the immunotherapy injection sites and in draining lymph nodes ${ }^{34}$.

In similar clinical protocols, dense lymphocyte infiltrates were observed at injection sites in the majority of patients ${ }^{35}$. In our study, we observed an increased infiltration of cytotoxic cells such as NK cells and CD8+ lymphocytes (Fig. 3b-d). Interestingly, the expression of NK receptor ligands was described on cervical tumor cells ${ }^{36}$, suggesting that NK cells can recognize and kill these cells. In a mouse model, tumor protection induced by GM-CSF was shown to be CD8 T cell dependent ${ }^{37}$ and the persistence of HPV16 infection was associated with the lack of cytotoxic T lymphocyte response in human ${ }^{38}$. As already described in other immunotherapy protocols ${ }^{39}$, we observed Foxp $3^{+}$Treg cells in cervical biopsies (Fig. 4). These cells could inhibit the anti-tumoral response ${ }^{40}$, but GM-CSF treatment did not induce a significant increase of these cells (Fig. 4). 
A systemic cellular immune response against HPV16 VLP and E7 protein was observed in all HPV16+ patients after GM-CSF applications (Fig. 5 a-b). In 2 patients (G4 and G5), the number of IFN $\gamma^{+}$cells dropped at week 23-42 after the treatment (Fig. 5a-b), suggesting that a larger GM-CSF therapeutic window could be beneficial in sustaining the immune response, but we could not exclude a regulatory role of $T$ cells in this inhibition since the number of Treg Foxp3+ cells slightly increased in some patients (Fig. 4). In some HPV16 negative patients, we also observed an immune response against HPV16 VLP, but not against HPV16 E7 (data not shown). Cross-reactivity has already been reported in PBMC from HPV-16 VLP vaccine recipients who can respond to L1-VLP from heterologous HPV types, suggesting the presence of conserved $T$ cell epitopes ${ }^{41}$. In contrast with VLP vaccines, which induce type-restricted immunity, the immune effect of GM-CSF is likely to be present for all the HPV genotypes. However, we were not able to confirm this statement because VLP and E7 proteins were not available for all the HPV types present in our cohort of patients.

Concerning the clinical response, we analyzed patients with LSIL because the treatment of the lesion can be postponed without danger for the patient. Due to spontaneous and rapid regression rate in these patients ${ }^{25}$, we were unable to show an effect of the treatment in this small cohort of patients.

In conclusion, our study demonstrated the safety of our therapeutic approach and suggested that GM-CSF induces DC/LC, CTL and NK cell recruitment in the lesion and the induction of a systemic immune 
response (humoral and cellular) against HPV. These results justify further analysis of this local immunotherapy protocol in a larger number of subjects.

\section{Acknowledgements}

We thank P. Roncarati, R. Gathy, E. Dortu and A-C. Lagrost for their excellent technical assistance and $\mathrm{Dr}$ S.L. Giannini and $\mathrm{Dr} \mathrm{M}$. Moutschen for helpful discussion. We are also grateful to Dr. P. PhamTrong from Greiner for HPV genotyping and to Dr. P. Coursaget for the provision of baculovirus expressing L1 HPV16 and HPV31. This study was supported by the Marshall Program of the Walloon Region, a grant from the Walloon Region (Colvir Project), the Belgian Fund for Medical Scientific Research, the L. Fredericq Fund, and the Centre AntiCancereux près l'Universite de Liège. P. Delvenne and N. Jacobs are supported by the Belgian National Fund for Scientific Research (FNRS). V. Renoux and B. Bisig are supported by a Télévie grant from the FNRS. 


\section{References}

1 Bosch FX: HPV vaccines and cervical cancer. Ann Oncol 2008;19 Suppl 5:v48-51.

2 Hildesheim A, Herrero R, Wacholder S, Rodriguez AC, Solomon D, Bratti MC, Schiller JT, Gonzalez P, Dubin G, Porras C, Jimenez SE, Lowy DR: Effect of human papillomavirus 16/18 L1 viruslike particle vaccine among young women with preexisting infection: a randomized trial. Jama 2007;298:743-753.

3 Petry KU, Scheffel D, Bode U, Gabrysiak T, Köchel H, Kupsch E, Glaubitz M, Niesert S, Kühnle H, Schedel I: Cellular immunodeficiency enhances the progression of human papillomavirus-associated cervical lesions. International journal of cancer 1994;57:836-840.

4 Welters MJ, de Jong A, van den Eeden SJ, van der Hulst JM, Kwappenberg KM, Hassane S, Franken KL, Drijfhout JW, Fleuren GJ, Kenter G, Melief CJ, Offringa R, van der Burg SH: Frequent display of human papillomavirus type 16 E6-specific memory tHelper cells in the healthy population as witness of previous viral encounter. Cancer research 2003;63:636-641.

5 Scott M, Stites DP, Moscicki AB: Th1 cytokine patterns in cervical human papillomavirus infection. Clin Diagn Lab Immunol 1999;6:751-755.

6 Samson SL, Bentley JR, Fahey TJ, McKay DJ, Gill GH: The effect of loop electrosurgical excision procedure on future pregnancy outcome. Obstet Gynecol 2005;105:325-332.

7 Prato B, Ghelardi A, Gadducci A, Marchetti I, Di Cristofano C, Di Coscio G, Bevilacqua G, Genazzani AR: Correlation of recurrence rates and times with posttreatment human papillomavirus status in patients treated with loop electrosurgical excision procedure conization for cervical squamous intraepithelial lesions. Int $J$ Gynecol Cancer 2008;18:90-94.

8 Al-Saleh W, Delvenne P, Arrese Estrada JE, Nikkels AF, Pierard GE, Boniver J: Inverse modulation of intraepithelial Langerhans cells and stromal macrophage populations in human papillomavirus-associated squamous intraepithelial lesions of the cervix. Virchows Arch 1995;427:41-48.

9 Giannini SL, Hubert P, Doyen J, Boniver J, Delvenne P: Influence of the mucosal epithelium microenvironment on Langerhans cells: Implications for the development of squamous intraepithelial lesions of the cervix. International journal of cancer 2002;97:654659.

10 Hubert P, Evrard B, Maillard C, Franzen-Detrooz E, Delattre L, Foidart JM, Noel A, Boniver J, Delvenne P: Delivery of granulocytemacrophage colony-stimulating factor in bioadhesive hydrogel stimulates migration of dendritic cells in models of human papillomavirus-associated (pre)neoplastic epithelial lesions. Antimicrobial agents and chemotherapy 2004;48:4342-4348.

11 Colasante A, Castrilli G, Aiello FB, Brunetti M, Musiani P: Role of cytokines in distribution and differentiation of dendritic 
cell/Langerhans' cell lineage in human primary carcinomas of the lung. Hum Pathol 1995;26:866-872.

12 Hubert P, Giannini SL, Vanderplasschen A, Franzen-Detrooz E, Jacobs N, Boniver J, Delvenne P: Dendritic cells induce the death of human papillomavirus-transformed keratinocytes. FASEB $J$ 2001;15:2521-2523.

13 Manna PP, Mohanakumar T: Human dendritic cell mediated cytotoxicity against breast carcinoma cells in vitro. J Leukoc Biol 2002;72:312-320.

14 Verra N, Jansen R, Groenewegen G, Mallo H, Kersten MJ, Bex A, Vyth-Dreese FA, Sein J, van de Kasteele W, Nooijen WJ, de Waal M, Horenblas S, de Gast GC: Immunotherapy with concurrent subcutaneous GM-CSF, low-dose IL-2 and IFN-alpha in patients with progressive metastatic renal cell carcinoma. British journal of cancer 2003;88:1346-1351.

15 Baur M, Schernhammer E, Gneist M, Sevelda P, Speiser P, Hudec M, Dittrich C: Phase I/II study of oral etoposide plus GM-CSF as second-line chemotherapy in platinum-pretreated patients with advanced ovarian cancer. British journal of cancer 2005;92:10191025.

16 Chianese-Bullock KA, Irvin WP, Jr., Petroni GR, Murphy C, Smolkin M, Olson WC, Coleman E, Boerner SA, Nail CJ, Neese PY, Yuan A, Hogan KT, Slingluff CL, Jr.: A multipeptide vaccine is safe and elicits T-cell responses in participants with advanced stage ovarian cancer. J Immunother 2008;31:420-430.

17 Dalstein V, Merlin S, Bali C, Saunier M, Dachez R, Ronsin C: Analytical evaluation of the PapilloCheck test, a new commercial DNA chip for detection and genotyping of human papillomavirus. Journal of virological methods 2008;in press.

18 Hubert P, Caberg JH, Gilles C, Bousarghin L, Franzen-Detrooz E, Boniver J, Delvenne P: E-cadherin-dependent adhesion of dendritic and Langerhans cells to keratinocytes is defective in cervical human papillomavirus-associated (pre)neoplastic lesions. J Pathol 2005;206:346-355.

19 Hallez S, Simon P, Maudoux F, Doyen J, Noël JC, Beliard A, Capelle X, Buxant F, Fayt I, Lagrost A-C, Hubert P, Gerday C, Burny A, Boniver J, Foidart J-M, Delvenne P, Jacobs N: Phase I/II immunogenicity of a Human Papillomavirus (HPV) type 16 E7 protein-based vaccine in women with oncogenic HPV-positive cervical intraepithelial neoplasia. Cancer Immunol Immunother 2004;53:642-650.

20 Combita AL, Touze A, Bousarghin L, Sizaret PY, Munoz N, Coursaget $P$ : Gene transfer using human papillomavirus pseudovirions varies according to virus genotype and requires cell surface heparan sulfate. FEMS Microbiol Lett 2001;204:183-188.

21 Combita AL, Bravo MM, Touze A, Orozco O, Coursaget $P$ : Serologic response to human oncogenic papillomavirus types 16 , $18,31,33,39,58$ and 59 virus-like particles in colombian women with invasive cervical cancer. International journal of cancer 2002;97:796-803.

22 Gutschalk CM, Herold-Mende CC, Fusenig NE, Mueller MM: Granulocyte colony-stimulating factor and granulocyte-macrophage 
colony-stimulating factor promote malignant growth of cells from head and neck squamous cell carcinomas in vivo. Cancer research 2006;66:8026-8036.

23 Al-Saleh W, Delvenne P, Greimers R, Fridman V, Doyen J, Boniver $\mathrm{J}$ : Assessment of $\mathrm{Ki}-67$ antigen immunostaining in squamous intraepithelial lesions of the uterine cervix. Correlation with the histologic grade and human papillomavirus type. Am J Clin Pathol 1995;104:154-160.

24 Castellsague X, de Sanjosé S, Aguado T, Louie KS, Bruni L, Munoz J, Diaz K, Gacic M, Beauvais O, Albero G, Ferrer E, Byrne S, Bosch FX: HPV and cervical cancer in the World 2007 report. Vaccine 2007;25:C1-1229.

25 Plummer M, Schiffman M, Castle PE, Maucort-Boulch D, Wheeler CM: A 2-year prospective study of human papillomavirus persistence among women with a cytological diagnosis of atypical squamous cells of undetermined significance or low-grade squamous intraepithelial lesion. The Journal of infectious diseases 2007;195:1582-1589.

26 Castle PE, Schiffman M, Herrero R, Hildesheim A, Rodriguez AC, Bratti MC, Sherman ME, Wacholder S, Tarone R, Burk RD: A prospective study of age trends in cervical human papillomavirus acquisition and persistence in Guanacaste, Costa Rica. The Journal of infectious diseases 2005;191:1808-1816.

27 Stanley MA: Mechanism of action of Imiquimod. Papillomavirus Report 1999;10:23-29.

28 Garland SM: Imiquimod. Current opinion in infectious diseases 2003;16:85-89.

29 Gilson RJ, Shupack JL, Friedman-Kien AE, Conant MA, Weber JN, Nayagam AT, Swann RV, Pietig DC, Smith MH, Owens ML: A randomized, controlled, safety study using imiquimod for the topical treatment of anogenital warts in HIV-infected patients. Imiquimod Study Group. AIDS (London, England) 1999;13:2397-2404.

30 Wagstaff AJ, Perry CM: Topical imiquimod: a review of its use in the management of anogenital warts, actinic keratoses, basal cell carcinoma and other skin lesions. Drugs 2007;67:2187-2210.

31 van Seters $M$, van Beurden $M$, ten Kate FJ, Beckmann I, Ewing PC, Eijkemans MJ, Kagie MJ, Meijer CJ, Aaronson NK, Kleinjan A, Heijmans-Antonissen C, Zijlstra FJ, Burger MP, Helmerhorst TJ: Treatment of vulvar intraepithelial neoplasia with topical imiquimod. The New England Journal of Medicine 2008;358:1465-1473.

32 Hubert P, Herman L, Maillard C, Caberg JH, Nikkels A, Pierard G, Foidart JM, Noel A, Boniver J, Delvenne P: Defensins induce the recruitment of dendritic cells in cervical human papillomavirusassociated (pre)neoplastic lesions formed in vitro and transplanted in vivo. Faseb J 2007;21:2765-2775.

33 Davidson EJ, Boswell CM, Sehr P, Pawlita M, Tomlinson AE, McVey RJ, Dobson J, Roberts JS, Hickling J, Kitchener HC, Stern $\mathrm{PL}$ : Immunological and clinical responses in women with vulval intraepithelial neoplasia vaccinated with a vaccinia virus encoding human papillomavirus $16 / 18$ oncoproteins. Cancer research 2003;63:6032-6041. 
34 Simmons AD, Li B, Gonzalez-Edick M, Lin C, Moskalenko M, Du T, Creson J, VanRoey MJ, Jooss K: GM-CSF-secreting cancer immunotherapies: preclinical analysis of the mechanism of action. Cancer Immunol Immunother 2007;56:1653-1665.

35 Soiffer R, Hodi FS, Haluska F, Jung K, Gillessen S, Singer S, Tanabe K, Duda R, Mentzer S, Jaklitsch M, Bueno R, Clift S, Hardy S, Neuberg D, Mulligan R, Webb I, Mihm M, Dranoff G: Vaccination with irradiated, autologous melanoma cells engineered to secrete granulocyte-macrophage colony-stimulating factor by adenoviralmediated gene transfer augments antitumor immunity in patients with metastatic melanoma. J Clin Oncol 2003;21:3343-3350.

36 Textor S, Durst M, Jansen L, Accardi R, Tommasino M, Trunk MJ, Porgador A, Watzl C, Gissmann L, Cerwenka A: Activating NK cell receptor ligands are differentially expressed during progression to cervical cancer. Int J Cancer 2008;123:2343-2353.

37 Chang EY, Chen $\mathrm{CH}$, Ji H, Wang TL, Hung K, Lee BP, Huang AY, Kurman RJ, Pardoll DM, Wu T: Antigen-specific cancer immunotherapy using a GM-CSF secreting allogeneic tumor cellbased vaccine. International journal of cancer 2000;86:725-730.

38 Nakagawa M, Stites DP, Patel S, Farhat S, Scott M, Hills NK, Palefsky JM, Moscicki AB: Persistence of human papillomavirus type 16 infection is associated with lack of cytotoxic T lymphocyte response to the E6 antigens. The Journal of infectious diseases 2000;182:595-598.

39 Welters MJ, Kenter GG, Piersma SJ, Vloon AP, Lowik MJ, Berends-van der Meer DM, Drijfhout JW, Valentijn AR, Wafelman AR, Oostendorp J, Fleuren GJ, Offringa R, Melief CJ, van der Burg SH: Induction of tumor-specific CD4+ and CD8+ T-cell immunity in cervical cancer patients by a human papillomavirus type $16 \mathrm{E} 6$ and E7 long peptides vaccine. Clin Cancer Res 2008;14:178-187.

40 Zou W: Regulatory T cells, tumour immunity and immunotherapy. Nat Rev Immunol 2006;6:295-307.

41 Pinto LA, Viscidi R, Harro CD, Kemp TJ, Garcia-Pineres AJ, Trivett M, Demuth F, Lowy DR, Schiller JT, Berzofsky JA, Hildesheim A: Cellular immune responses to HPV-18, -31 , and -53 in healthy volunteers immunized with recombinant HPV-16 L1 virus-like particles. Virology 2006;353:451-462. 


\section{Figure legends}

Fig. 1: Schedule of enrollment.

Fig. 2: Proliferation of normal keratinocytes $(\mathrm{KN})$ and keratinocyte cell lines (means $\pm S D, n=3$ ) in presence of GM-CSF (a). Proliferation index (Ki67 staining) in biopsies of patients treated with GM-CSF or placebo gel (means $\pm S E, n=10$ for $G M-C S F$ and $n=5$ for placebo) $(\mathbf{b})$.

Fig. 3: Infiltration of $\mathrm{DC} / \mathrm{LC}\left(\mathrm{CD} 1 \mathrm{a}^{+}\right), \mathrm{CTL}\left(\mathrm{CD} 8^{+}\right)$and NK cells (NKp46+) in cervical LSIL. Ratio of CD1a ${ }^{+}$cells in the epithelium (a), of $\mathrm{CD}^{+}$cells in the epithelium (b) or in the stroma (c), of NKp46+ NK cells in the stroma (d) at visit D (week 2) and visit F (week 23-42) after application of GM-CSF or placebo gel. Empty symbols= patient G2.

Fig. 4. Foxp $3^{+}$Treg cells in cervical biopsies. Number of Foxp $3^{+}$cells in the epithelium before (visit $A / B$ ) or after (visit $D$, week 2 or visit $F$, week 23-42) applications of GM-CSF or placebo gel (a). Ratios of Foxp3 ${ }^{+}$ cells in the stroma at visit $\mathrm{D}$ and $\mathrm{F}$ (b). Empty symbols= patient $\mathrm{G} 2$.

Fig. 5: IFN $\gamma$ production in response to HPV16 E7 or HPV16 L1-VLP in HPV16 positive patients. PBMC were stimulated overnight with HPV16 E7 (a) or L1-VLP (b). (a) The percentage of IFN $\gamma^{+}$cells was determined in $\mathrm{CD}^{+}, \mathrm{CD}^{+}$or $\mathrm{CD} 56^{+} \mathrm{CD} 16^{+} \mathrm{CD}^{-}$(NK cells) gated cell populations. Antibody titers against HPV 16 (c) and HPV 31 (d) VLP in patient plasma samples. The antibody titer was determined in ELISA assay by serial dilutions of plasma samples. The assay was performed at least in duplicate. $\mathrm{BT}=$ before treatment. 